\title{
The Good, the Great, and the Exciting
}

\author{
Marvin L. Birnbaum, MD, PhD
}

\begin{abstract}
[We stay young . . . J . . by not seeking "success" in discussion or life, because success is de facto, a failure; an obstacle toward potential progress since it creates a rigid form that you are then bound to defend. Success usually denies access to new ideas, it makes you prone to discard potential or actual contradicting facts that you may interact with and thus, modify the "results" presumably achieved. Success represents a point of arrival, the cutting of a block that may be used by others for other buildings, but that for the achiever is very difficult to modify and, at best, only can be refined and polished.
\end{abstract}

Sergio Ivano Magalini, MD Prehospital and Disaster Medicine, 1990

Over the last several years as Editor-in-Chief of this prestigious medical journal, I have had substantial cause and opportunity to ponder the future of medical research, publishing, and medical information systems in general and Prehospital and Disaster Medicine ( $P D M$ ) in particular. Simultaneously, the explosion of technology has fostered the development of new methods for communicating information, especially with the advent of the boundless Information Superhighway. As Editor, I repeatedly confront the need to make the important information published in Prehospital and Disaster Medicine accessible to all those whose interests are fed by that submitted to and published in PDM. In addition, I have been party to the gradual development of the new medical science that is prehospital (out-of-hospital) and disaster medicine, and beginning with the landmark papers surrounding the Armenia and Loma Prieta earthquakes, watched the gradual inclusion of the qualitative research techniques that constitute the primary research technology used by the other social sciences into our evolving science. One message is clear: The scientific methods required for the study of out-of-hospital emergency medical care and the practice of disaster medicine require that medical investigators learn and accept these "softer" research techniques as a valuable part of medical research.

Unfortunately, there are those who do not accept these research techniques as "good" medical science or even as part of the medical sciences. This is the most likely reason this Journal was not accepted by the National Library of Medicine for inclusion in its Index Medicus. Although its value was rated better than during its last review (score increased from 2 to 3 [4 needed for inclusion]), the material published still did not meet the unknown, unpublished criteria held by the review panel for the Index. This failure on the part of the Index reviewers to understand what we do and the importance of what we do and how we must do it is unfortunate and short sighted, but is not disastrous or even damaging. Prehospital and Disaster Medicine fills an important niche in the medical literature and will continue to do so.

Out-of-hospital and disaster medicine is the practice of provision of emergency medical services within the public-health and epidemiologic sciences; and therefore, understanding what we do is essential to our practice. Through this understanding, we have come to know more about our practice and science than does any other part of medicine. Out-of-hospital and disaster-medicine research sets the example for other disciplines to follow, and we will not confine ourselves to the limited research savored by "pure" scientists. Our fellow scientists in the allied health sciences recognized our research through early inclusion of the materials published in PDM in the readily accessible Cumulative Index to Nursing and Allied Health (CINAHL) (also by DataStar, and DIALOG, and on CD-ROM through CD-Plus, Compact Cambridge, and Silver Platter). Only arrogance would prevent a researcher in the field of out-of-hospital and disaster medicine from pursuing the information in this readily available index (or the other indices) prior to initiating any research effort.

What does this really mean to all of $u s$ in the near and distant future? How will we access medical information so essential for us to continue our research efforts? I propose that the principal access to all medical literature will be through use of the Information Superhighway. This technology allows enhanced search techniques that go far beyond the few key words allowed by the current $\mathrm{MeSH}$ indexing systems. Access will be afforded through ability to search the more detailed volume indices as published in each of the medical journals, to scan for important phrases in the bodies of abstracts and even actual text. Current indexing systems will become obsolete.

The information published in Prehospital and Disaster Medicine will be accessible through the Home Web Page of the World Association for Disaster and Emergency Medicine and will have presence on the Jems Communications World Wide Web site (jems.com) by the time you are reading this editorial. Each of the abstracts, key words, indices, and other important information will be accessible through the burgeoning Information Superhighway. In addition, a complete CD-ROM version of $P D M$ will become available. We are in step with the evolving Superhighway.

This journal fills a role in defining our practice and daily influences on how we practice. Its direction is steady and exciting. Those who wish to continue in the ways of old certainly may do so, but those who wish to continue with the development of our own unique and essential science should hold on for the ride. We are ahead of our time.

What remains for those who profess themselves as good or even great medical researchers is to get their heads out of the sands of old and look to the future. The comfort of the old will leave these investigators in the dust of the past, for they only understand a small part of the great horizons opening for research. The rest of medical science needs to follow the path $P D M$ is blazing, for those who fail to recognize the path of the future no longer represent all that is wonderful. Prehospital and Disaster Medicine will continue to lead the way. 
Once one discards the possibility of joining churches, where can be found preconstituted and definitive answers, many people have chosen to go into Science, just to avoid the need for making qualitative judgments that always are of an ambiguous and equivocal nature. They have chosen to live in the tautological domain of quantitative answers that, in addition, offer them the advantage of removing any residual doubt about anything by statistical evaluation. As you can see, in many academic institutions, there has been a natural selection of a type of population, conservative in nature, that has been made more so by the success of this type of approach, since qualitative methods have paid such high dividends...In other words, they are old people.

Sergio Ivano Magalini, MD

Quality versus Quantity in Medical Research: Can

We Average Cheshire Cat Smiles?

Prehospital and Disaster Medicine, 1990;5:377-382. 